\title{
INCLUSIVE GROWTH BY MEANS OF SUSTAINABLE SUPPLY CHAINS: A CASE STUDY OF THE DABBAWALAS OF MUMBAI, INDIA.
}

\author{
Babu George \\ Fort Hays State University \\ Hays-67601, KS, USA \\ bpgeorge@,fhsu.edu
}

\begin{abstract}
As India emerges to become a major player in the global economy, it is essential to understand some of the unique business models that have emerged interacting with its cultural economy and found a place in its developmental trajectory. Of these, the dabbawalas of Mumbai is worth a special mention. The dabbawalas constitute a lunchbox delivery and return system that delivers hot lunches from homes and restaurants to people at work in India. Based on primary research and more recent literature, this paper provides updated perspectives on the dabbawala business with special focus on the sustainability of their business model. It discusses the dabbawala system performance along multiple aspects of sustainability. The basis of competitive advantage of the dabbawala business model is presented an emergent phenomenon from the cultural logic of the ecosystem.
\end{abstract}

KEYWORDS: Social entrepreneurship, food, home delivery, supply chain, sustainability, inclusiveness, India

JEL CLASSIFICATION: L31, O35, A13

DOI: $10.2478 / \mathrm{IJEK}-2018-0010$

Received: $8^{\text {th }}$ February, 2018

1st Revision: $4^{\text {th }}$ June, 2018

Accepted: $10^{\text {th }}$ July, 2018

Reference: George, B (2018). Title of the paper. Inclusive growth by means of sustainable supply chains: A Case study of the Dabbawalas of Mumbai, India. International Journal of Entrepreneurial Knowledge 6(2), 5-11. doi: 10.2478/IJEK-2018-0010

\section{INTRODUCTION}

The dabbawalas ("lunchbox deliverymen") originated in the late colonial times as individual, independent, entrepreneurs. They were organized as a cooperative in late $19^{\text {th }}$ century. Indian employees working for the British did not like the food being served in the workplace and this was their first trigger (Date, 2006). They started with the objective of giving a livelihood for migrant workers coming mostly from the villages surrounding Mumbai; from the very beginning they practiced community referral based staff recruitment (Pathak, 2010).

Currently, they are a distributed, flat, self-governed, network organizational structure, with around 5000 members/employees. In the three-layered structure, all employees are paid equally. The organizational culture is characterized by discipleship and not followership. This culture is known to nurture individualized customer care, collaborative planning, and implementation. They take pride in strong teamwork and strict time-management (North \& Kumta, 2014).

Straightforward application of the mainstream theories of value and competence are found to be inadequate to explain their accomplishments. This case study of the dabbawalas aims to identify the bases of their competitive advantage from perspectives ranging from their historical roots, continued community spirit, sustainability orientation, and the various nuanced conditions in the business 
environment.

\section{LITERATURE REVIEW}

\subsection{The Advantage of Business Networks}

Cooperative networks and other grassroots level movements that can be fitted broadly into the banner of the third way of development have come under extensive critical scrutiny (Giddens, 2013; Leftwich, 1993). Especially in small rural communities, cooperative networks formed by the community members have caused what may be described as a business renaissance. The developmental vision of such networks is an emergent phenomenon formed out of a negotiated process involving various interest groups. This process is embedded in the milieu provided by the social capital binding these interest groups together.

There exists a wide variety of networking arrangements (Gnyawali \& Madhavan, 2001). The difference among these arrangements can be explained in terms of four characteristics; coverage, form, mode, and motive. Coverage refers to the extensiveness of an alliance in terms of functional competencies and geographical coverage. The form ranges from non-equity agreements to the opposite where alliance members buy equity stakes in other alliance members. The third characteristic, the mode, describes the intrinsic vs extrinsic nature of the relationship among the members. Motives refer to the underlying reason for the creation of an alliance.

In typical capitalistic settings, the centralized power of financial capital creates formal business structures that are fundamentally exploitative in nature (Honig, 1998). Participation for inclusive development, on the other hand, depends on the existence of the relationship gravity of the society, the social capital. It is not that cooperative business structures are impossible in low social capital settings. Actually, in capitalistic societies, it is known that cooperative networks are formed by capitalistic interests as a criticism dampening adaptancy platform. The conciliatory aura of the networked model may help the exploitative businesses to hide their unsustainable practices. In the case of dabbawalas, their network is more a reflection of the internal dynamics of a society than the expressionism of an approval seeking corporate house. A lot of what we call sustainability is still non-inclusive (Hahn \& Figge, 2011): the realization of inclusive sustainability without external pressures is rate to be found and the dabbawala model epitomizes it.

\subsection{The Dabba Delivery System}

Dabbawalas, each serving around 30 customers per day, works under the leadership of a 'mukadam' (supervisor). They have time-tested and perfected their hub-n-spoke concept. Each spoke is managed autonomously by a team of 20-25. Over the time, this 'hospitality network' evolved into a flawless system with six sigma performance rating (Isher, \& Bhal, 2005; Karthi et al., 2015).

Dabbas are collected from homes or from the dabba makers to a sorting place, where the lunch boxes are sorted into groups based on the destination. The grouped boxes are then carried to the coaches of trains. Destination station dabbawalas pick these groups and deliver them. Later in the day, the empty lunchboxes are carried back to their places of origin. A combination of colors and symbols help dabbawalas to identify pertinent delivery instructions. The lunch boxes have the following identifiers on them: Dabba origination point; abbreviated location name; name of the railway station nearest to the origination point, color-coded; name of the railway station nearest to the destination point, colorcoded; and, identifiers for destination building and floor, for the benefit of the destination dabbawala handling the lunchbox (Ghodake, 2016). Their system creates the unique situation of circular distribution with supplier and the supplied often indistinguishable: something like a zero-order closed loop supply chain. 
There is no division of labor and every dabbawala is an undivided part of the whole (Pathak, 2010). The entire process of sorting and delivery happens at a pace unimaginable for most of us without using advanced automation techniques. It is estimated that there is no more than one mistake in every millionth transaction carried out by them. The dabbawalas do not use GPS routing, barcodes, or RFIDs. The dabbawalas may not speak English or may not have attended schools; but, they are not illiterate about their labor (Chopra \& Sharma, 2012). Their nonmainstream literacy is part of their inimitable success and competitive advantage, notes Krishnan (2014).

and other grassroots level movements that can be fitted broadly into the banner of the third way of development The author is allowed to choose whether and to what extent these subdivisions are necessary.

\subsection{Community Based Business Model for Sustainable Development}

Dabbawalas evidence that sustainability is a 'process in the making'. One of their sustainable innovations in the making includes the introduction of dabbas (food boxes) made of more eco-friendly materials (boxes made of wood rather than steel/aluminum, better sealing to avoid contamination in the transportation phase, no to plastic). In exceptional cases, they deliver restaurant-cooked food to workplaces and even to homes. While resisting the temptation to exploit an increasing opportunity to do the same, they rather encourage home-cooked food from trusted neighborhood homes (livelihood for more families!) They deliver organic raw materials for food preparation to homes, often directly from the farmers (inside the otherwise empty dabbas) in the evenings - an instance of 'sustainable' reverse logistics with integration to 'sustainable' second order supply chains. They collect leftovers from hotels and event locations and deliver to the orphanages and old age homes. Likewise, they collect leftovers in the dabbas to deliver to farmers who use them as manure. Their support for household waste disposal support is well known; also, they support women with cloth washing (dhobi). They have started up with opening up of in-house canteens in factories, business offices, and schools (and also the Indianization of menus of multinational fast-food chains).

The Dabbawalas engage in complementary and supplementary pro-community activities. They help circulate community support messages (E.g., About medical camps, volunteering and employment opportunities, etc.). They organize community activism (E.g., Mobilization of people against the corrupt; against unsafe garbage dumping; tree planting; etc.). These add-on activities make an $11 \mathrm{am}$ $2 \mathrm{pm}$ job to a full day job for the network members.

Recently, they have entered into a new arena: making and mending relationships: (E.g.: match-making). They know very closely about the localities that they serve and provide early warning to law enforcement about troubles in an area. They have been quite progressive about the induction of women / LGBT / minority groups into the member network. They offer part-time continuing educational opportunities for society members. Opportunities for training in computer operations, food service, personal grooming, English language, etc., are provided. Healthcare facilities and retirement planning for the members of the cooperative are provided. They help start, nurture, and certify dabbawalla networks in other cities. They are active in knowledge exchange with colleges and bschools on dabbawalla network building in particular and social entrepreneurship in general.

\section{METHODOLOGY}

A part of this case study draws from an earlier analysis carried out by the present researcher in 2011 2012 (George, 2012). The study is broadly informed by the qualitative research tradition. Semistructured interviews, participant observations, and focus groups were the primary sources of information. Additional primary data was gathered again during 2016-2017, in order to gain insights about improvements in business practices. Twenty-seven dabbawallas were interviewed. The researcher travelled with them while they returned after delivering the dabbas and gathered responses. In this process, the delivery system components were observed, both as an insider (emic perspective) and as an 
outsider (etic perspective). Later, seven dabbawalas were included in a focus group during which the preliminary observations made above were refined for theoretical saturation. Logbooks and customer observations on social media were examined, too. Insights from published works on the dabbawala business model complemented these.

\section{FINDINGS}

\subsection{Organic Development of a Sustainable Business}

Analysis of the qualitative data indicates that a deeply shared vision of sustainability is built into the Dabbawala business model. The following characteristics are embedded into it:

- Organic development of business

- Not in response to regulatory pressure nor to 'capitalize upon' the green wave of consumer demand

- Not deliberately introduced as a means for competitive advantage

- No imported theories or practices

- Even the dabba coding system is self-evolved/evolving

- Coexistence with community aspirations

- Indian culture gives a lot of importance to 'homemade food'

- Co-evolution with society; nevertheless, act as a force against undesirable developments (such as fast food culture).

- Resonates with the voices of nature and society

- Nopen, paper, or electronic memory documentation

- All depends upon a few characters of 'code' marked on dabbas

- Avoid using motorized / private transportation for shipping

- Resilience-homeostasis keep tested: community does not disown the network even when they were allured by commercially minded similar service providers.

- Some employers are known to give their staff incentives if they use dabbawala services rather than go out to have lunch in the restaurants.

- Maybe, love delivered from home make them efficient and effective

\subsection{Sustainable Competitive Advantage: What the Dabbawalas Think}

Focus groups helped to elucidate the following four key themes:

- Work is worship

- "delivering food is a way to serve God"

- "I am delivering love, packaged in food"

- "Me skipping lunch will go in vain if a single one of my customers goes without lunch"

- See the whole through the part

- "If I fail, all other dabbawalas will fail"

- "I will pass only if all other dabbawalas pass the test every day"

- "Process is the outcome"

- Trust is critically important

- "Trust broken once is broken forever"

- Simplicity works

- "Simplicity is not the best solution, but it always works"

The dabbawalas have the first mover advantage associated with building a huge network. They benefit from network economics: benefit for each user increases with the size of the network. There is no room for a parallel network and that adds to their agility. Their algorithm of success lies latently in the web of relationships: their core competence cannot easily be decoded, transferred, or replicated. There 
is a culture of competitiveness: superior match between internal resources and external opportunities, obtained through shared understanding between 'the servant and the served'.

Competition for limited space on trains has grown into a major problem for the expansion of the dabbawala model. Mumbai is a 'victim of its own success'. Changing worldviews and lifestyles of the young generation has created a depletion of the supply of the labor force. Nuclear families, trendiness to eat out, frugality no longer a virtue, spouse accepting full-time employment, etc., pose additional problems. Also, businesses are moving to satellite towns around Mumbai which are not well connected by suburban trains (also, temporary offices, telecommuting, etc.).

\section{DISCUSSION}

While the overall story of dabbawalas of Mumbai has been widely discussed in the academic circles (Chakraborty \& Hargude, 2015; Menon \& Raithatha, 2012; Patel \& Vedula, 2006; Percot, 2005; Roncaglia, 2017), their contribution upon sustainable development has not received adequate attention. Dabbawalas epitomize the triumph of human will that is fueled by the power of certain living philosophies (Nirali \& Vijaylaxmi, 2014). The traditional dabbawala business model built upon frugal and reverse innovation ensured sustainability for the bottom of the pyramid. The dabbawalas have no strategy but an implicit sense of shared purpose that directs their collective action (Thakur, 2015). The fitness of a business model to local cultures results in greater productivity, engagement, and low turnover, observe (Behrens, Singh \& Bhandarker, 2016).

With increasing living expenses and the cost of delivery, the dabbawalas need additional revenue streams to survive (Baindur \& Macário, 2013). The business model streamlining is indeed a strongly felt need (Sivarak, 2017). In this regard, some potential avenues include:

- Carry commercials and samples inside dabbas

- Mail delivery

- Paint dabbas with advertisements

- Product endorsements

- Dabbawala owned restaurants with food take-out outlet

Modernization need not be an enemy of sustainability (Rosca, Arnold, \& Bendul, 2017). Yet, some fear that dabbawalas should resist every kind of externally imposed or imported change. The dabbawalas are imbued with a sense of autonomy and accountability not explicable by the western ideas of management and Raste (2016) calls this "spirituality at the bottom of the pyramid". They grew tremendously big, yet maintained the characteristics of micro-enterprises, ensuring inclusive growth. This makes the dabbawala model an intransferable benchmark in urban logistics. Driven by the cultural and structural embeddedness of organically developed ideas of perfection, every dabbawala is in competition with himself for better standards. This simultaneous dynamic of competition with themselves and cooperation with others in the network offers intriguing potential for future research.

\section{CONCLUSIONS}

The dabbawalas give a very unique twist to community-based entrepreneurship. This paper has attempted to examine the case of dabbawalas within the context of the extant literature on business networks and sustainable development. The 'third way' of development espoused by this model is driven by motivations other than corporate profit and shareholder wealth. It leads to a balanced distribution of the wealth among the members of the cooperative while serving an important yet traditionally unmet need of the society.

One of their key inimitable strengths is the organic development of not just their organizational culture but also their business strategies. While the traditional literature would place a heavy premium upon planned development and execution on strategies, the agility that an organization gains by interacting 
with the various elements in the business environment - the 'survival of the fittest, overcoming hostile evolutionary forces and aligning with the favorable headwinds - are much more sustainable and longer lasting (Farjoun, 2002).

Three generations of dabbawalas made this business model work. But, will next generation be interested to accept this as a career option? A Project with tech-savvy young employees on an 'express delivery system' using electronic distribution technologies is in the experimental stage. E-commerce in food delivery (web-based booking, SMS based ordering and tracking, etc.) is a serious initiative. Experimentation is done with 'table services' by trade-school trained dabbawalas.

Will these lead to an erosion of their core competence? Will the 'MBAs as managers' create a cultural divide between the dabbawalas on the road and the managers sitting in the corporate building? A lot of unsought (sometimes unwanted) help comes to the dabbawalas from academic researchers and gurus. Unfortunately, not much of their jargon makes sense for the illiterate tribe of street-smart dabbawalas.

No doubt, a crucial question that might be going through the minds of the dabbawala top brasses is whether their reputation as an impeccable social enterprise will be negatively affected or whether their key strengths will be diluted. We need to wait and see. Still, with the appointment of a few professionally trained administrators and the introduction of scientific managerial practices, the dabbawalas hope to keep pace with the times.

\section{REFERENCES}

Baindur, D., \& Macário, R. M. (2013). Mumbai lunch box delivery system: A transferable benchmark in urban logistics? Research in transportation economics, vol. 38(1), 110-121.

Behrens, A., Singh, P., \& Bhandarker, A. (2016). View from Practice: Managing Effectively in Collectivist Societies: Lessons from Samba Schools and Dabbawalas. Thunderbird International Business Review, vol. 57, no. 1, pp. 37-51.

Chakraborty, A., \& Hargude, A. N. (2015, August). Dabbawala: Introducing Technology to the Dabbawalas of Mumbai. In Proceedings of the 17th International Conference on HumanComputer Interaction with Mobile Devices and Services Adjunct (pp. 660-667). ACM.

Chopra, R., \& Sharma, H. (2012). Corporate to Cooperative Entrepreneurial Leadership in Emerging Economy-Lessons from Indian Enterprises. Journal of Organisation and Human Behaviour, 1(4), 12-28.

Date, V. (2006). Travails of an Ordinary Citizen: A Tale from Mumbai. Economic and Political Weekly, vol. 7 , no. 1, pp. 3473-3476.

Farjoun, M. (2002). Towards an organic perspective on strategy. Strategic management journal, vol. 22, no. 7 , pp. 561-594.

George, B.P. (2012). Sustainable Supply Chain Management: An Updated Case Study of Dabbawalas of Mumbai. Society for Marketing Advances (SMA) Conference, Special Session Presentation, held in Orlando, FL, USA during November 2012.

Ghodake, S. T. (2016). Transcending Life through Romance: Mumbai Tiffinwalas and the Lunch Box. Advances in Social Sciences Research Journal, vol. 3, no. 12, pp. 8-15.

Giddens, A. (2013). The third way and its critics. John Wiley \& Sons.

Gnyawali, D. R., \& Madhavan, R. (2001). Cooperative networks and competitive dynamics: A structural embeddedness perspective. Academy of Management review, vol. 26, no. 3, pp. 431-445.

Hahn, T., \& Figge, F. (2011). Beyond the bounded instrumentality in current corporate sustainability research: Toward an inclusive notion of profitability. Journal of Business Ethics, vol. 104, no. 3, pp. 325-345.

Honig, B. (1998). What determines success? Examining the human, financial, and social capital of Jamaican microentrepreneurs. Journal of business venturing, vol. 13, no. 5, pp. 371-394. 
Isher, A. S., \& Bhal, H. (2005). Factor Study of Human Reliability and Industrial Productivity: Comparison of Food Delivery System. In ASQ World Conference on Quality and Improvement Proceedings (Vol. 59, p. 495). American Society for Quality.

Karthi, S., Devadasan, S. R., Murugesh, R., Sreenivasa, C. G., \& Sivaram, N. M. (2012). Global views on integrating Six Sigma and ISO 9001 certification. Total Quality Management \& Business Excellence, vol. 23, no. 1, pp. 3-4, 237-262.

Krishnan, U. S. (2014). A Cross Cultural Study of the Literacy Practices of the Dabbawalas: Towards a New Understanding of Nonmainstream Literacy and its Impact on Successful Business Practices (Doctoral dissertation, Kent State University).

Leftwich, A. (1993). Governance, democracy and development in the Third World. Third World Quarterly, vol. 14, no. 3, pp. 605-624.

Menon, S., \& Raithatha, M. (2012). Occupational stress: An analytical study of stress among dabbawalas of Mumbai Tiffin Suppliers Association. Prabandhan: Indian Journal of Management, vol. 5, no. $1,47-54$.

Nirali, P., \& Vijaylaxmi, C. (2014). Small Innovations: The Big Drivers of Indian Economic Development. Advances in Management, vol. 7, no. 1, pp. 20-21.

North, K., \& Kumta, G. (2014). On the Way to a Knowledge Society. In Knowledge Management (pp. 1-29). Springer, Cham.

Patel, N., \& Vedula, N. (2006). Dabbawalas of Mumbai. White Paper Kenan-Flagler Business School, vol. 1, no. 1, pp. 5-7.

Pathak, G. S. (2010). Delivering the Nation: The Dabbawala s of Mumbai. South Asia: Journal of South Asian Studies, vol. 33, no. 2, pp. 235-257.

Percot, M. (2005). Dabbawalas, tiffin carriers of Mumbai: answering a need for specific catering. vol. 5, no. 3, pp. 25-37.

Raste, A. (2016). Spirituality at the Bottom of the Pyramid. In Ethical Leadership (pp. 255-260). Palgrave Macmillan, London.

Roncaglia, S. (2017). Feeding the City: Work and Food Culture of the Mumbai Dabbawalas (p. 232). Open Book Publishers.

Rosca, E., Arnold, M., \& Bendul, J. C. (2017). Business models for sustainable innovation-an empirical analysis of frugal products and services. Journal of Cleaner Production, vol. 162, no.1, 133-145.

Sivarak, O. (2017). Global Supply Chain in Asia. In Internationalization and Managing Networks in the Asia Pacific, vol. 19, no. 2, pp. 99-121.

Thakur, R. (2015). Community marketing: serving the base of the economic pyramid sustainably. Journal of Business Strategy, vol. 36, no. 4, pp. 40-47. 